\title{
La mort et nous (par la bande dessinée)
}

\section{Jean Martin}

Dr med., membre de la rédaction

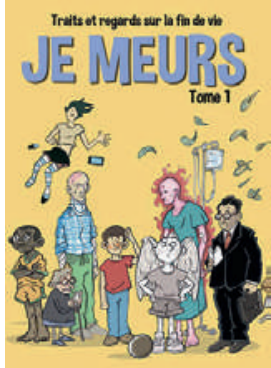

Je meurs

Traits et regards sur la fin de vie tome 1

Vevey: Fondation

La Chrysalide

et Hélice Hélas

Editeur; 2015

60 pages. $28 \mathrm{CHF}$

ISBN 978-2-940522-29-7
La Fondation La Chrysalide est un centre de soins palliatifs ouvert à La Chaux-de-Fonds en 1998 et qui depuis 2006 fait partie de l'Hôpital neuchâtelois. Elle a pour mission de promouvoir la qualité de l'accompagnement en fin de vie dans les lieux de soins (domicile, institutions, hôpitaux).

Dans une démarche originale, la fondation a publié en 2012 une brochure qui a retenu l'attention, A la vie... à la mort!, rassemblant des contributions sur «l'avant», «l'autour de» et «l'après» la mort - avec témoignages, textes de professionnels, informations pratiques. $\mathrm{Pu}$ blication qui à l'époque a été incluse comme supplément des 40000 exemplaires des principaux journaux de la région [1]. Dans un esprit semblable de communication avec le public, elle publie en 2015 une série de trois bandes dessinées, en touchant les mêmes thématiques.

Je meurs est la première, qui vient de sortir: treize histoires courtes, par des auteurs de bandes dessinées de notre pays. Elle met l'accent prioritairement sur les sentiments de la personne qui meurt mais ceux des proches apparaissent aussi; la deuxième, Tu meurs, évoquera ceux des personnes qui perdent un être cher tandis que la troisième, Il meurt, abordera les rapports à la mort en général. Je meurs est un album de 60 pages. Le Dr Ph. Babando, président de la fondation, en signe la préface dans laquelle il raconte la trajectoire d'un cancéreux telle qu'il a pu en suivre dans sa pratique souhaitant que cette BD ait valeur de "remerciement pour toutes les personnes qui de près ou de loin accompagnent un être dans sa dernière trajectoire».

Les contributions sont de styles divers et se passent dans des endroits et contextes divers. Certaines décrivent/incluent le milieu médical et hospitalier. La première, touchante, illustre le dialogue de petits-enfants avec un grand-père dont la santé décline. Il y a celle de l'adolescent victime d'un grave AVC, de ses parents à son chevet et des soignantes dont les efforts n'éviteront pas l'issue fatale. Une femme jeune mourante qui pense aux rapports avec ses proches, à leur douleur, à sa colère («de n'avoir pas su guérir, qu'on me parle de tout et de rien comme si tout allait bien, contre moi même d'exiger que vous acceptiez l'inacceptable»). Des dialogues entre le patient et son corps qui a mal, qui cache des choses, qui ne veut plus bouger (est absent), qui s'affaiblit, qui «m'attire vers les grands fonds». Une BD évoque le chagrin amoureux d'une jeune fille, ses pulsions suicidaires puis, comme des clips télévisuels dont on parle en ce moment, la voit écrasée par une voiture alors qu'elle consulte son iPhone. Une est située en Afrique dans un contexte d'exactions violentes. Des grands-mères sont à plusieurs reprises au centre du récit; ainsi, fille et petite-fille visitant dans son EMS une patiente qui glisse dans un état de type Alzheimer. Des processus de deuil. Enfin, dernière BD de la plaquette, évocation d'un patient "mort durant quelques minutes» après un accident de voiture et qu'on parvient à réanimer sans séquelle neurologique - «'étais [à nouveau] vivant.»

La plupart de ces histoires sont réalistes. Certaines ont une dimension plus ou moins onirique, fantasmée: rencontre avec la Mort faucheuse ou pincée de sciencefiction, avec survenue d'engins spatiaux et d'animaux fantastiques... On trouve aussi le fameux tunnel au bout duquel luit la lumière. Le dessin va du «bien propre sur soi", si je peux dire, à des styles très originaux, parfois poétiques, parfois côtoyant le trash.

On retrouve, explicitement ou entre les lignes, les stades popularisés par Elisabeth Kübler Ross dans la confrontation à la maladie grave: surprise/dénégation, colère, marchandage, dépression, acceptation. Ce qui va rendre plus fructueux à mon sens l'usage pédagogique possible de ces histoires.

Parmi les publications qui fleurissent autour de la fin de vie, Je meurs retiendra l'attention du public familier/ adepte de bandes dessinées, mais pas seulement. Cet album se prêtera bien à utilisation/animation dans des groupes de jeunes ou dans les écoles, en stimulant réactions, réflexions, discussions, compositions écrites. Je veux croire qu'elle rencontrera le succès et que sera insuffisant le premier tirage de 1500 exemplaires. Et je me réjouis de voir les deux $\mathrm{BD}$ qui suivront.

\section{Référence}

1 Martin J. «A la vie... à la mort!» (la Chrysalide dissémine un document). Revue médicale suisse. 2013;9:291 